\title{
Design of a Probabilistic Based Software Tool for Evaluating Controllability, Observability and Testability Models of Digital Systems
}

\author{
A. Ahmad*, M. A. K. Rizvi, A. Al-Lawati, D. Al-Abri and M. Awadalla \\ Department of Electrical and Computer Engineering, College of Engineering, Sultan Qaboos University, \\ P. O. Box 33, Postal Code 123; Muscat, Sultanate of Oman; afaq@squ.edu.om; lawati@squ.edu.om, \\ alabrid@squ.edu.om, medhatha@squ.edu.om,m099399@student.squ.edu.om
}

\begin{abstract}
This paper presents a probabilistic based software tool for estimation of digital systems' testability. The tool allows fast computation to estimate testability in linear time complexity regarding the number of components and interconnects of the digital system. The designed tool is based on utilization of controllability and observability measurement for the estimation of overall system's testability. The algorithmic procedures are tested, verified and demonstrated through a large number of simulated digital systems. As examples some of the simulated results are embedded in this paper.
\end{abstract}

Keywords: Controllability, Digital System, MATLAB, Observability, Probability, Testability

\section{Introduction}

Digital devices have become a hot topic of interest and research ${ }^{1-7}$. Major techniques like Fault Diagnosis, Design for Test (DFT), Built-In Self-Test (BIST) and Scan methods are being heavily researched ${ }^{8-28}$. Some of the basic foundation of these methods depends on the knowledge of the analytical modelling of the controllability and the observability of the Digital System Under Test (DSUT). Further, the study of the probabilistic model of the DSUT eases the problem in identifying the weak links in the digital system. Thus, it becomes important to understand these concepts and have a tool to help in obtaining their values for any given digital system. In this paper, the concept is first understood and then a software tool is developed and implemented using MATLAB.

\section{Background Knowledge}

\subsection{Probabilistic Modeling}

Probabilistic modeling is based on the probabilistic nature of each logic gates in the digital system. The modeling gives the possibility of obtaining a 0 or a 1 at each node of the digital system ${ }^{29-31}$. Digital electronics has just two possible states of 0 and 1 . The probabilities of these two states are represented by $P(0)$ and $P(1)$. Thus the following relation is obtained.

$$
\begin{array}{lll}
P(0) & P(1) & 1
\end{array}
$$

The probability is calculated using the concepts from mathematics and set theory. Consider an ideal - two input AND gate as given in Figure 1. The probability of logic 1 at the two inputs is taken as 0.5 , that is; $P\left(i_{1}\right)=P\left(i_{2}\right)=0.5$. The probability of logic 1 at the output of an AND gate; $P_{2}(1)$ is the product of $P\left(i_{1}\right)$ and $P\left(i_{2}\right)$.

$$
\begin{array}{llllll}
P_{2}(1) & P\left(i_{1}\right) & P\left(i_{2}\right) & 0.5 & 0.5 & 0.25
\end{array}
$$

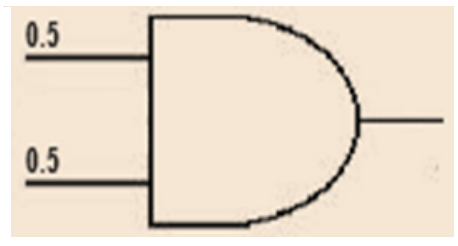

Figure 1. Two input AND gate. 
Where the subscript ' 2 ' in $P_{2}(1)$, indicates having 2 inputs. Similarly, the probability for an AND gate with three and four input lines are given below respectively in Equations (3) and (4).

$$
\begin{array}{cccccc}
P_{3}(1) & 0.5 & 0.5 & 0.5 & 0.125 \\
P_{4}(1) & 0.5 & 0.5 & 0.5 & 0.5 & 0.9325
\end{array}
$$

Thus for an $\mathrm{n}$ input AND gate, the probability of obtaining a logic 1 at the output can be given by,

$$
P_{n}(1) \quad P\left(i_{1}\right) \quad P\left(i_{2}\right) \ldots \ldots P\left(i_{n}\right)
$$

Implementing this concept of mathematics and set theory, the complete relationships of various logic gates are obtained as given in Table 1.

\subsection{Controllability and Observability}

Controllability and observability are very important concept for the understanding the testability of any digital system. The importance of these concepts have been realized since the 1970s and one of the first papers, which had formed the foundation for controllability and observability, was by L.H. Goldstein in $1979^{32}$. This has been extensively used by various researchers to study and develop testability measures throughout the years.

Controllability is defined as the difficulty of setting a signal line to a required logic value from primary inputs $^{30-33}$. In other words, it means, the number of nodes that must be set/reset to obtain the required logic value at the given node. It is well known that digital systems can have a value of either 0 or 1 . Controllability of obtaining logic 1 and controllability of obtaining logic 0 are denoted by $\mathrm{CC} 1$ and $\mathrm{CCO}$ respectively. According to the convention used, the measuring value ranges from 1 to $\infty$ (infinity), with 1 being the easiest to control and as the value becomes higher, the difficulty is increased.

The controllability modeling of any digital systems starts from the input side of the digital system. Consider a two input AND gate with inputs a and $b$. To obtain a logic 0 at the output, $z$, either input a or input $b$ or both must

Table 1. Probabilistic model of logic gates

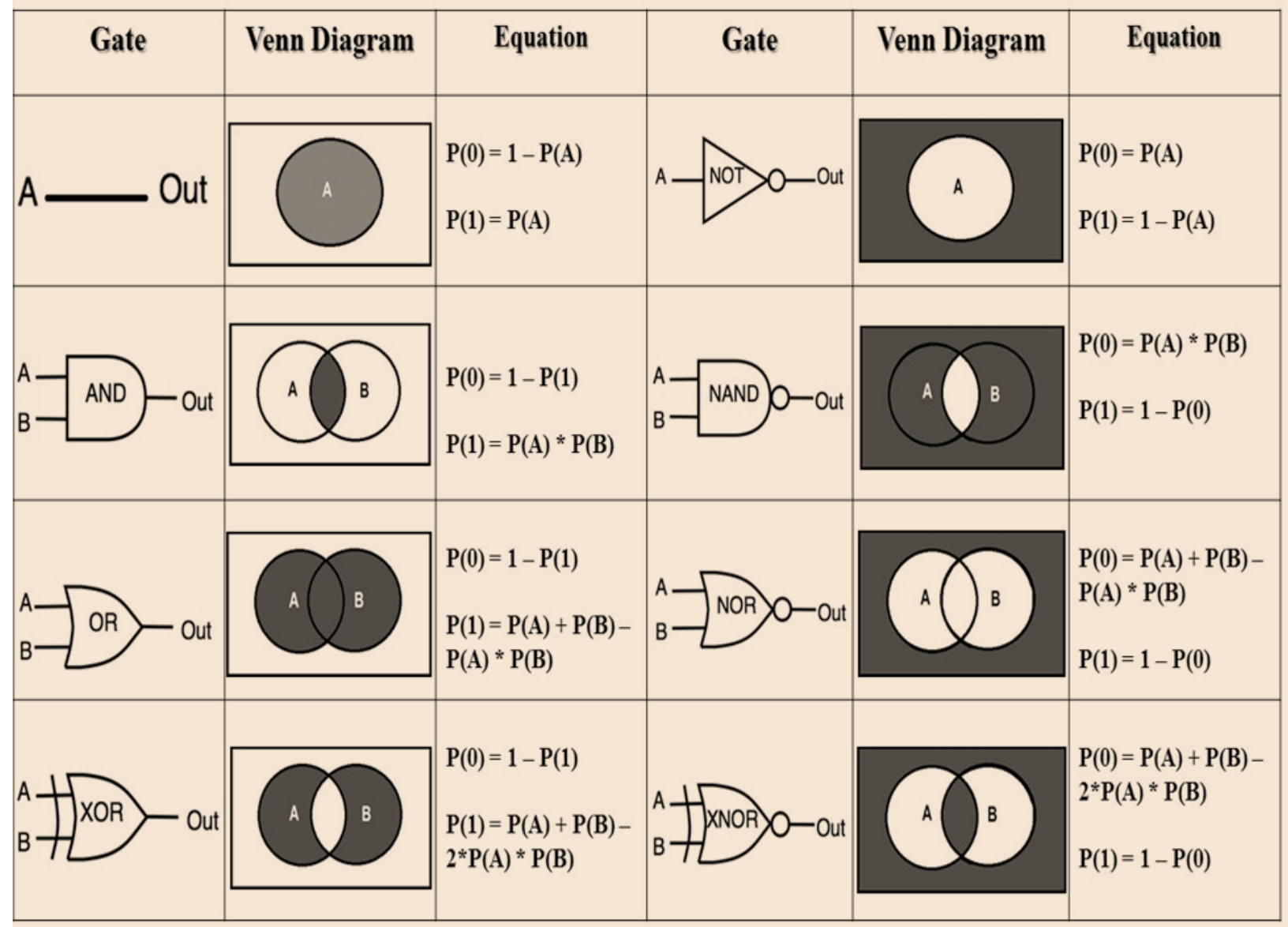


be at logic 0 , which depends on the ease of controlling a or b. To obtain a logic 1 at the output of the AND gate, both input nodes are required to be set to logic 1 . The generalized relations are thus given by the Equations (6) and (7) and are described below.

$$
\begin{gathered}
C C O(Z) \quad \min C C O(a), C C O(b) \quad 1 \\
C C 1(Z) \quad C C 1(a) \quad C C 1(b) \quad 1
\end{gathered}
$$

Observability is defines as the difficulty of propagating the logic value of the signal line to primary outputs ${ }^{32,33}$. This means that it is a value which gives the number of nodes that must be set or reset to justify the logic value of given node which is observed at the primary output. As a convention, the values of observability range from 0 to $\infty$ (infinity), where the most easily observable is given the value of 0 and as the difficulty to observe increases, the observability value also increases.

The observability modeling of any digital systems starts from the output side of the digital system and is quantifiable only after the controllability modeling has been completed. Consider the two input AND gate given in Figure 2 with inputs denoted by $a$ and $b$. For an AND

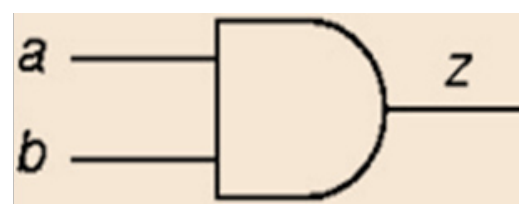

Figure 2. AND gate. gate, to be able to observe node at the input side, all the other inputs must be at logic 1 . By this, the value at that input line is propagated into the output line. Thus, for AND gate, all other input lines are to be controlled to make their value to logic 1 before the concerned node under observation can be observed. The generalized relation is thus given by Equation (8).

$$
\text { CO(a) } \quad \operatorname{CO}(z) \quad C C 1(b) \quad 1
$$

For a fan-out the relation is given as below

$$
\mathrm{C} 0(\mathrm{a}) \min \mathrm{C} 0(\mathrm{z} 1), \mathrm{C} 0(\mathrm{z} 2), \ldots, \ldots, \mathrm{C} 0(\mathrm{zn})
$$

This similar understanding can be applied to all other logic gates to obtain their respective relationships for computing CCO, CC1 and CO. Table 2 and 3 describes the relationships controllability and observability respectively.

\subsection{Testability}

Testability is defined as the approximate measure of the difficulty to test a particular node in the digital system. To measure this value, it is required to know the difficulty of setting a node to logic 0 or 1 using the primary inputs (controllability) and the difficulty of observing the concerned node using the primary outputs (observability). To test a node for the stuck at logic 0 fault, the node must be set to logic 1 and then observed. Thus, the testability of a node for stuck at logic 0 fault is the sum of

\begin{tabular}{|c|c|c|c|c|c|c|c|c|}
\hline \multirow{3}{*}{$\begin{array}{l}\text { Gate } \\
\text { AND }\end{array}$} & \multicolumn{8}{|c|}{ Controllability } \\
\hline & \multicolumn{4}{|c|}{ CCO } & \multicolumn{4}{|c|}{ CC1 } \\
\hline & $\min C C O(a), C C 0(b)$ & 1 & & & $C C 1(a) \quad C C 1(b) \quad 1$ & & & \\
\hline OR & $C C O(a) \quad C C 0(b) \quad 1$ & & & & $\min C C 1(a), C C 1(b)$ & 1 & & \\
\hline XOR & $\min \quad C C 0(a) \quad C C 0(b$ & , $C C 1(a)$ & $C C 1(b)$ & 1 & $\min \quad \operatorname{CCO}(a) \quad C C 1(b)$ & $\mathrm{CCO}(a)$ & $C C 1(b)$ & 1 \\
\hline NAND & $C C 1(a) \quad C C 1(b) \quad 1$ & & & & $\min C C 0(a), C C 0(b)$ & 1 & & \\
\hline NOR & $\min C C 1(a), C C 1(b)$ & 1 & & & $C C 0(a) \quad C C 0(b) \quad 1$ & & & \\
\hline XNOR & $\min \quad C C 1(a) \quad C C 0(b)$ & , $C C 0(a)$ & $C C 1(b)$ & 1 & $\min \quad \operatorname{CCO}(a) \quad C C O(b)$ & , $\operatorname{CC1}(a)$ & $C C 1(b)$ & 1 \\
\hline NOT & $C C 0(z) \quad C C 1(a) \quad 1$ & & & & $\operatorname{CC1}(z) \quad C C 0(a) \quad 1$ & & & \\
\hline
\end{tabular}
the node's controllability of logic 1 and the observability. Similarly, the testability of a node for stuck at logic 1 fault

Table 2. Relationships for controllability 
Table 3. Relationships for observability

\begin{tabular}{llllllll}
\hline \multirow{2}{*}{ Gate } & \multicolumn{7}{c}{ Observability } \\
\cline { 2 - 7 } AND & $C 0(z)$ & $C C 1(b)$ & 1 & $C 0(z)$ & $C C 1(a)$ & 1 \\
OR & $C 0(z)$ & $C C 0(b)$ & 1 & $C 0(z)$ & $C C 0(a)$ & 1 \\
XOR & $C 0(z)$ & $\min \quad C C 0(b), C C 1(b)$ & 1 & $C 0(z)$ & $\min \quad C C 0(a), C C 1(a)$ & 1 \\
NAND & $C 0(z)$ & $C C 1(b)$ & 1 & $C 0(z)$ & $C C 1(a)$ & 1 \\
NOR & $C 0(z)$ & $C C 0(b)$ & 1 & $C 0(z)$ & $C C 0(a)$ & 1 \\
XNOR & $C 0(z)$ & $\min \quad C C 0(b), C C 1(b)$ & 1 & $C 0(z)$ & $\min \quad C C 0(a), C C 1(a)$ & 1 \\
NOT & $C 0(a)$ & $C 0(z)$ & 1 & & & \\
\hline
\end{tabular}

is the sum of the node's controllability of logic 0 and the observability. The derived equations for testability at node for the stuck at logic 0 fault and for the stuck at logic 1 fault are presented in Equations (10) and (11) respectively.

$$
\begin{aligned}
& \text { Testability (s a } 0) \text { CC1 C0 } \\
& \text { Testability (s a 1) CC0 C0 }
\end{aligned}
$$

Using the above given equations we can compute testability. These computed testability values can be used to provide the analysis of difficulty of testing the internal digital system's parts which helps to understand any requirements of redesigning or adding of special testing hardware. It also provides the guidance for the algorithms performing test pattern generation by avoiding the use of hard-to-control lines. Testability also provides an estimation of fault coverage and test vector length.

\section{Software Tool Development}

To calculate the various values and to generate the respective system's model for controllability, observability and the probability at each node, a software tool has been developed. The tool is scripted in MATLAB ${ }^{30,31,33-35}$ programming language. Ensuing section describes about the data structure used for the description of digital system.

\subsection{System Description}

The program of the developed tool uses text files to obtain the data structure of the system's description to calculate parameters of the given digital system. The format used

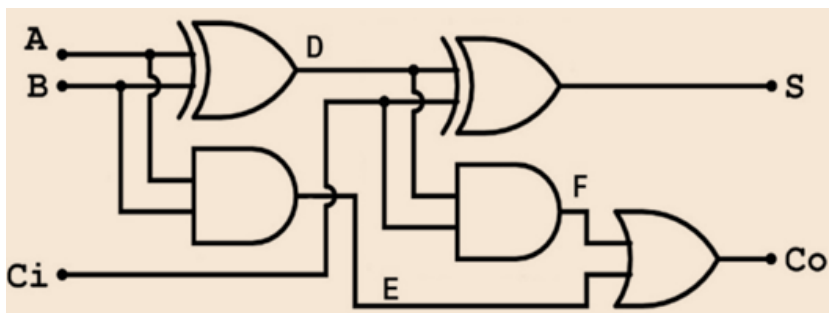

Figure 3. Full adder digital system.

in the program is explained and demonstrated with an example of a digital system below. The considered example is a full adder whose digital system is shown in Figure 3. The demonstration is depicted and explained in Table 4. Each value of the data-string is separated using '|'.

Thus, from Table 4, the final description of the digital system of Figure 3 is given below.

$3|0.5| 0.5|0.5| 1|1| 1|3| 2|s 2,1| s 3,1|2| 2|i 1| i 2 \mid$ xor|2|i1|i2|and $|2| 2|s 1,1|$ i3 |xor|2|s1,1|i3|and $1|2| s 2,2|s 1,2|$ or $\mid$

\subsection{Modeling Tool}

The method of modelling the digital system by describing its data structure based on the software tool developed has been discussed in the Section 3.1. Once the digital system data is inputted, the tool then applies algorithms, explained in Figures 4, 5 and 6, to compute the probability, controllability and observability models for the digital system respectively.

On running the program, it asks the user for the address of the text file where the details of the digital system is stored in. It then extracts the digital system's data 
Table 4. Data description of the digital system of Figure 3

\begin{tabular}{|c|c|c|c|c|}
\hline \multirow{2}{*}{$\begin{array}{l}\text { Step } \\
1\end{array}$} & \multicolumn{3}{|r|}{ Description } & Data \\
\hline & \multicolumn{3}{|c|}{ Number of Primary Inputs } & 3 \\
\hline 2 & \multicolumn{3}{|c|}{ Probabilities of having a logic ' 1 ' at each input } & $0.5,0.5 \& 0.5$ \\
\hline 3 & \multicolumn{3}{|c|}{ Controllability of each input line } & $1,1 \& 1$ \\
\hline 4 & \multicolumn{3}{|c|}{ Number of levels in the digital system } & 3 \\
\hline 5 & \multicolumn{3}{|c|}{ Number of Primary Outputs } & 2 \\
\hline 6 & \multicolumn{3}{|l|}{ Primary Output lines } & s21 \& s31 \\
\hline \multirow[t]{18}{*}{7} & \multirow{18}{*}{$\begin{array}{l}\text { Definition the digital } \\
\text { system structure }\end{array}$} & \multicolumn{2}{|c|}{ Number of gates level 1} & 2 \\
\hline & & \multirow{6}{*}{$\begin{array}{l}\text { Define } \\
\text { Gates }\end{array}$} & Number of inputs to gate 1 & 2 \\
\hline & & & Input lines & i1 \& i2 \\
\hline & & & Gate type & xor \\
\hline & & & Number of inputs to gate 2 & 2 \\
\hline & & & Input lines & i1 \& i2 \\
\hline & & & Gate type & and \\
\hline & & \multicolumn{2}{|c|}{ Number of gates level 2} & 2 \\
\hline & & \multirow{6}{*}{$\begin{array}{l}\text { Define } \\
\text { Gates }\end{array}$} & Number of inputs to gate 1 & 2 \\
\hline & & & Input lines & s11 \& i3 \\
\hline & & & Gate type & xor \\
\hline & & & Number of inputs to gate 1 & 2 \\
\hline & & & Input lines & s11 \& i3 \\
\hline & & & Gate type & and \\
\hline & & \multicolumn{2}{|c|}{ Number of gates level 3} & 1 \\
\hline & & & Number of inputs to gate 1 & 2 \\
\hline & & & Input lines & s22 \& s12 \\
\hline & & & Gate type & or \\
\hline
\end{tabular}

structure and then applies the mathematical relationships, discussed in the earlier sections, to calculate the probabilities of each node of the digital system to build the complete probability model of the digital system. The data in the file is then used to compute the controllability of each node of the digital system and generate the complete controllability model. The mathematical relationships, as discussed in the earlier sections, are applied to compute the value. Once the controllability model is completed, the observability is built using the controllability values and the concerned mathematical relationships discussed in earlier sections. For every node, once the observability is computed, the program checks if the current node is one of the output line. In that case, the calculated observability for the node is void and the value given is 0 . The program then checks for the fan-in/fan-out condition by selecting the minimum value as the value of observability for the current node. 


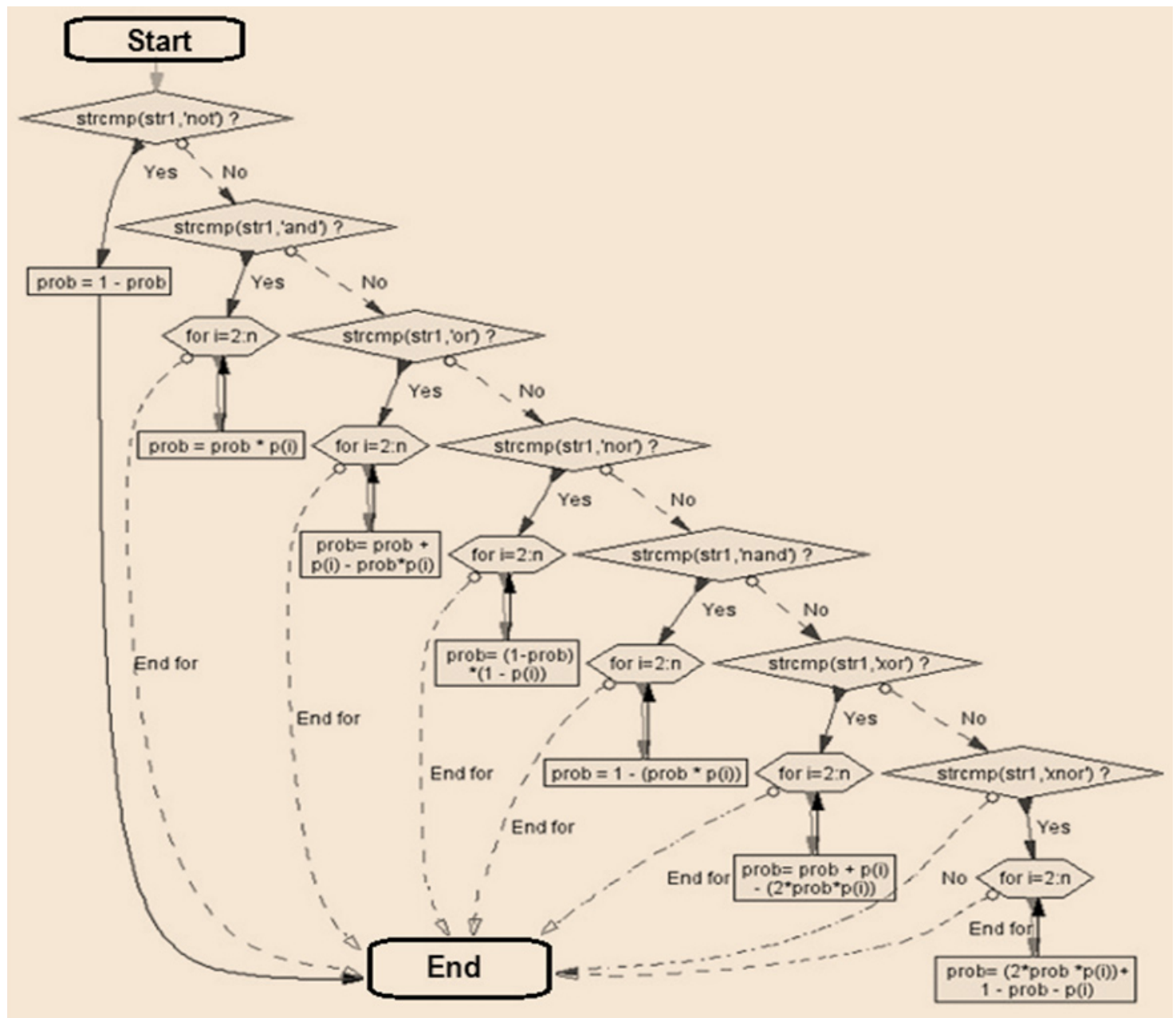

Figure 4. Flowchart to build the probabilistic model.

\section{Results}

Once these models are generated, the program then stores the results into the destination file address provided by the user. Table 5 demonstrates the simulation result for the digital system shown in Figure 3. The final output obtained on running the software tool, scripted in MATLAB, is given in Figure 7.

Using the developed software tool, the testability for other digital systems have also been simulated and tested. The results obtained for basic digital systems like 3x8 decoder, $4 \times 2$ multiplexer and 4-bit comparator have been shown in Figures 8, 9 and 10 respectively.

\section{Conclusion}

A software tool has been developed and successfully implemented. The tool is applied to generate the models for various digital systems such as adder, decoder, comparator and multiplexer. Also, many other digital systems having non-regular structures picked from benchmark circuits are tested satisfactorily. The developed software tool can help to determine the test parameters and methodologies for a given digital system to make it testable. This tool can further be extended to incorporate various features like test pattern generation algorithms that can use the computed testability values to generate an optimal test for a given digital system under test. 


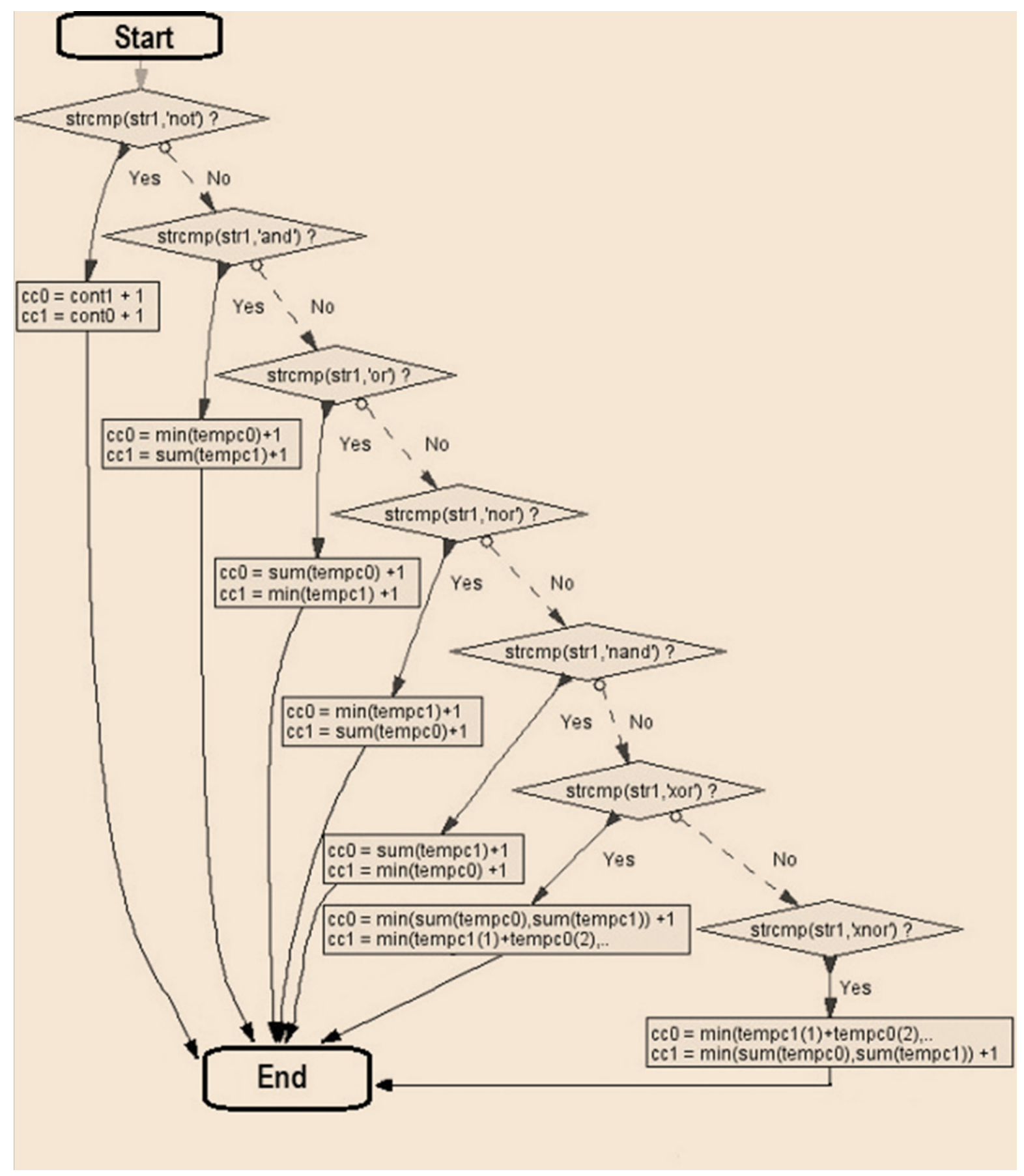

Figure 5. Flowchart to build the controllability model. 


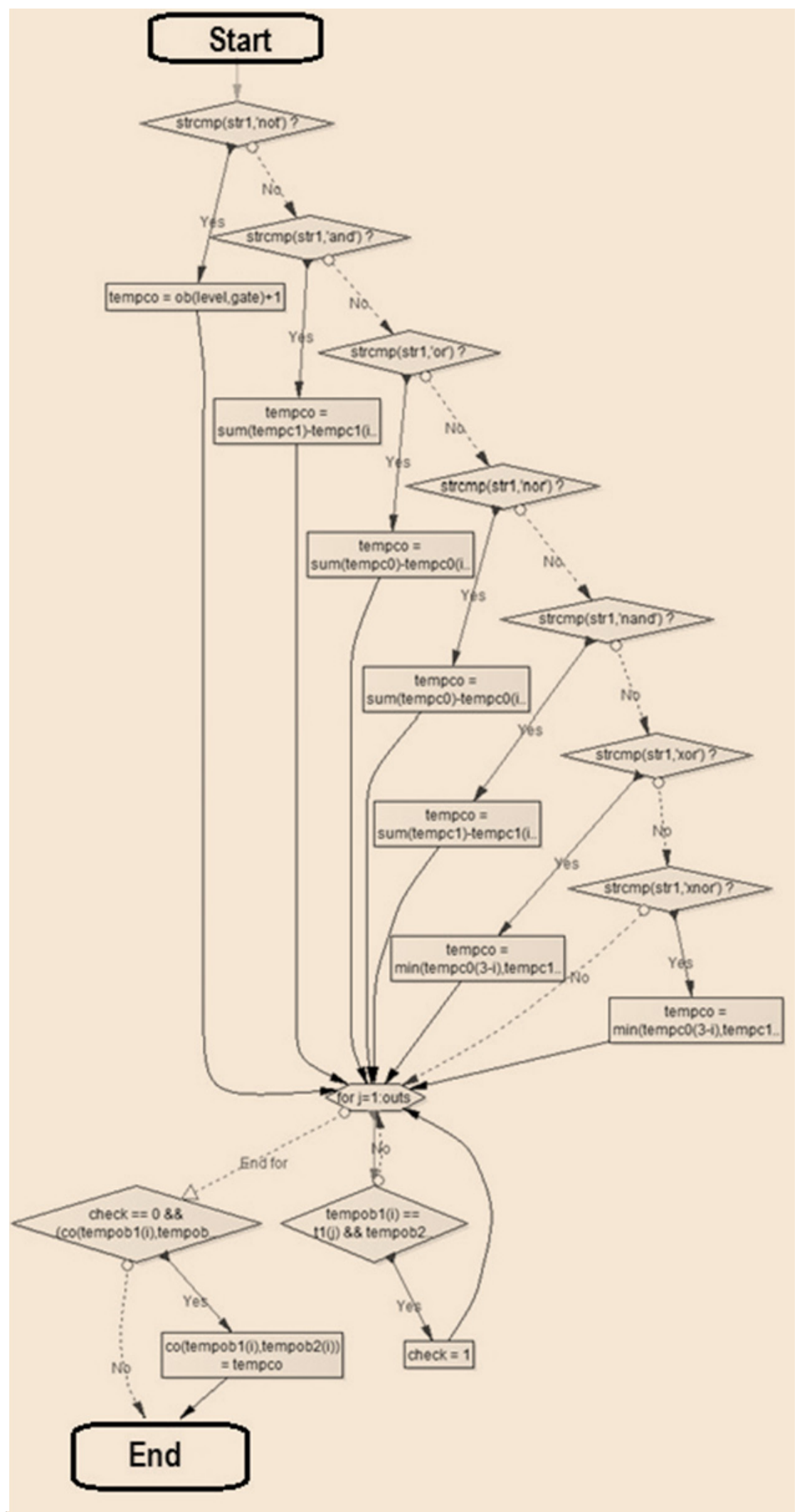

Figure 6. Flowchart to build the observability model. 
Table 5. Simulation result for Figure 3

\begin{tabular}{|c|c|c|c|c|c|c|c|}
\hline \multirow[t]{2}{*}{ Node } & \multirow[t]{2}{*}{$\mathrm{P}(0)$} & \multirow[t]{2}{*}{$\mathrm{P}(1)$} & \multirow[t]{2}{*}{$\mathrm{CC} 0$} & \multirow[t]{2}{*}{$\mathrm{CC} 1$} & \multirow[t]{2}{*}{$\mathrm{CO}$} & \multicolumn{2}{|c|}{ Testability } \\
\hline & & & & & & $s-a-0$ & s-a-1 \\
\hline A & 0.5000 & 0.5000 & 1 & 1 & 4 & 5 & 5 \\
\hline B & 0.5000 & 0.5000 & 1 & 1 & 4 & 5 & 5 \\
\hline $\mathrm{Ci}$ & 0.5000 & 0.5000 & 1 & 1 & 4 & 5 & 5 \\
\hline $\mathrm{D}$ & 0.5000 & 0.5000 & 3 & 3 & 2 & 5 & 5 \\
\hline $\mathrm{E}$ & 0.7500 & 0.2500 & 2 & 3 & 3 & 6 & 5 \\
\hline $\mathrm{F}$ & 0.5000 & 0.5000 & 5 & 5 & 0 & 5 & 5 \\
\hline$S$ & 0.7500 & 0.2500 & 2 & 5 & 3 & 8 & 5 \\
\hline $\mathrm{C}_{0}$ & 0.5625 & 0.4375 & 5 & 4 & 0 & 4 & 5 \\
\hline
\end{tabular}

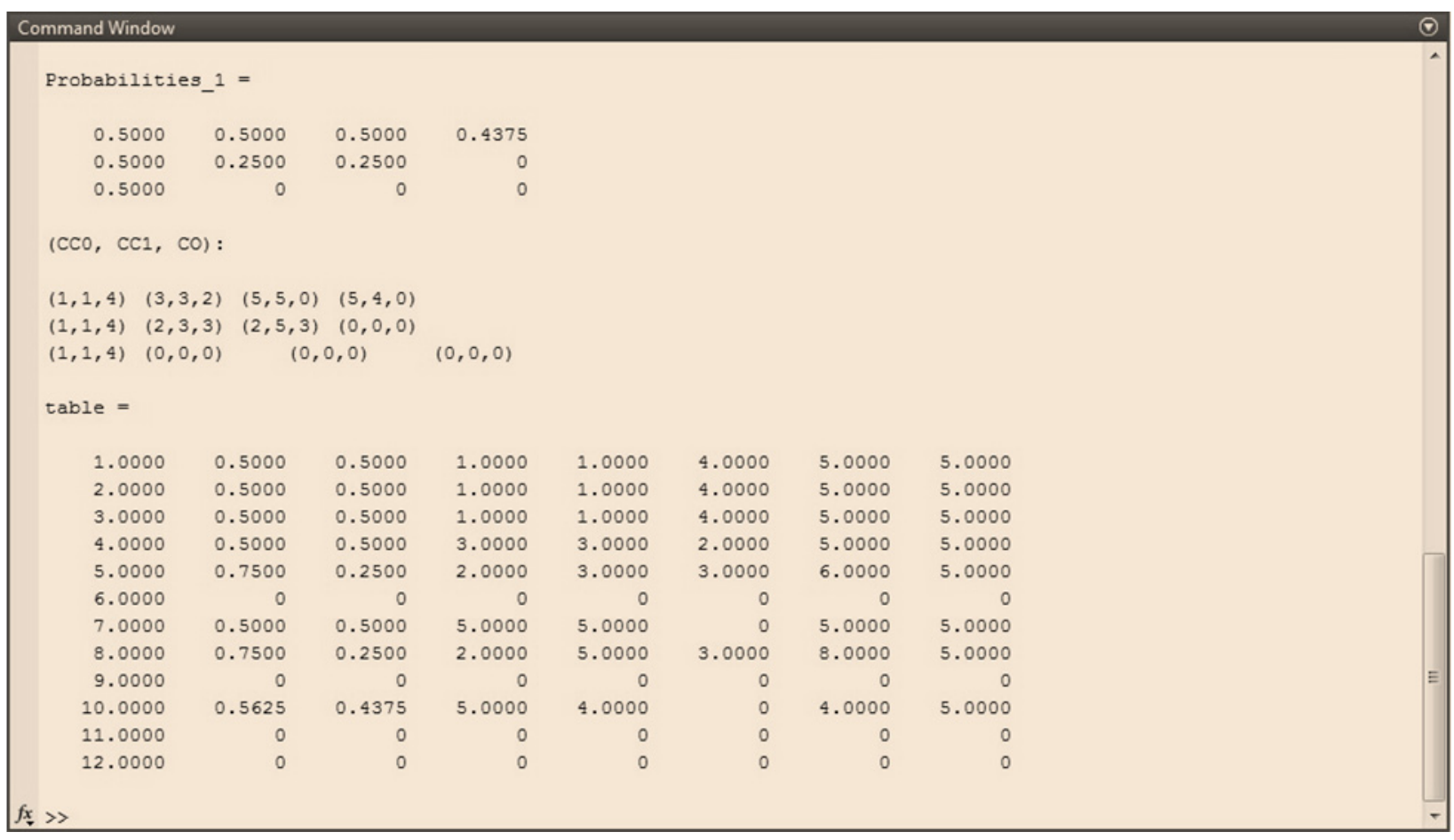

Figure 7. Output for testability model of Figure 3 - MATLAB window. 


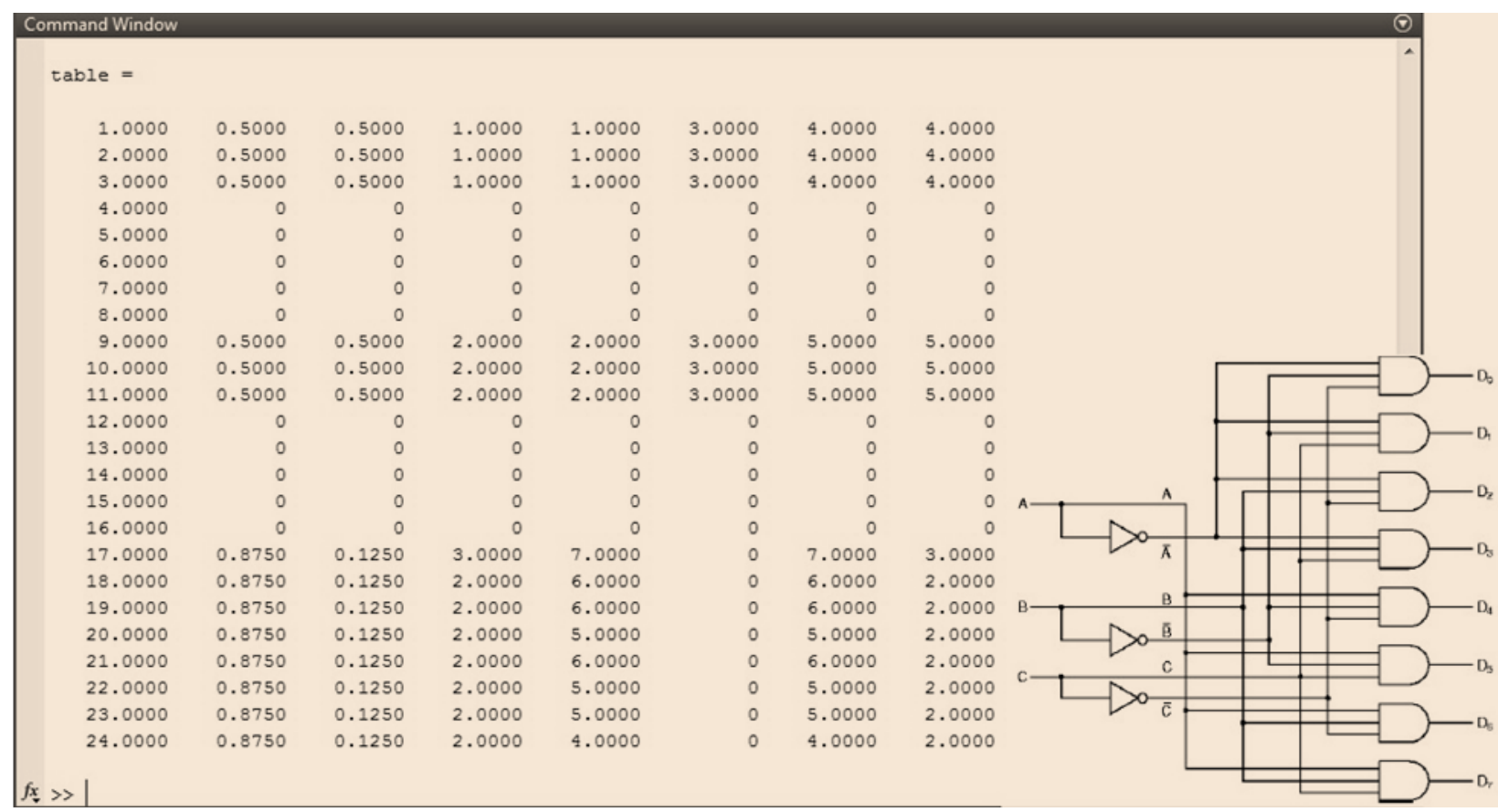

Figure 8. Output for testability model of a 3x8 decoder - MATLAB window \& digital system.

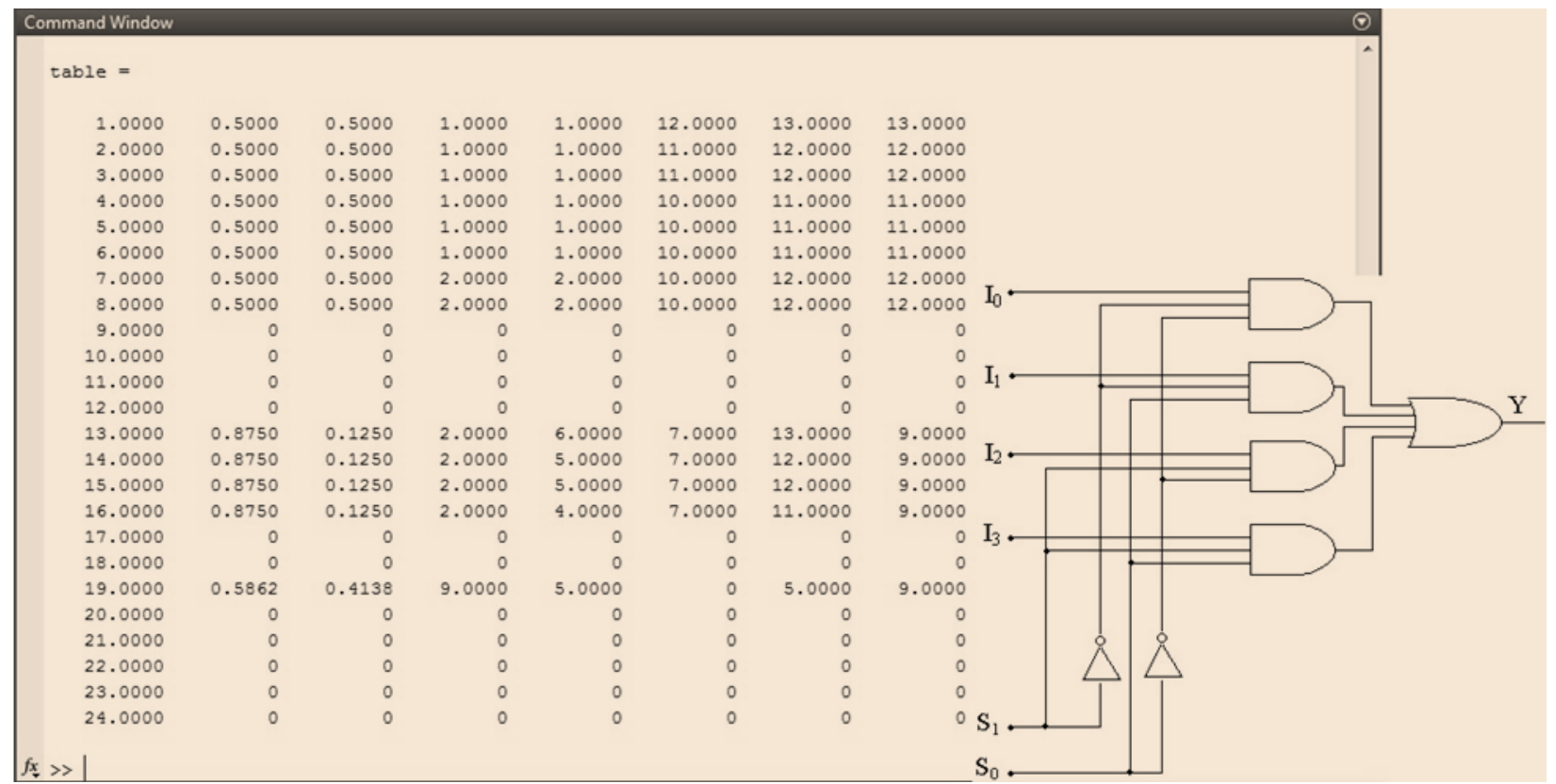

Figure 9. Output for Testability Model of a 4x2 MUX - MATLAB window \& digital system. 


\begin{tabular}{|c|c|c|c|c|c|c|c|}
\hline \multicolumn{8}{|l|}{ Command Window } \\
\hline \multicolumn{8}{|l|}{ table $=$} \\
\hline 1.0000 & 0.5000 & 0.5000 & 1.0000 & 1.0000 & 13.0000 & 14.0000 & 14.0000 \\
\hline 2.0000 & 0.5000 & 0.5000 & 1.0000 & 1.0000 & 13.0000 & 14.0000 & 14.0000 \\
\hline 3.0000 & 0.5000 & 0.5000 & 1.0000 & 1.0000 & 18.0000 & 19.0000 & 19.0000 \\
\hline 4.0000 & 0.5000 & 0.5000 & 1.0000 & 1.0000 & 18.0000 & 19.0000 & 19.0000 \\
\hline 5.0000 & 0.5000 & 0.5000 & 1.0000 & 1.0000 & 22.0000 & 23.0000 & 23.0000 \\
\hline 6.0000 & 0.5000 & 0.5000 & 1.0000 & 1.0000 & 22.0000 & 23.0000 & 23.0000 \\
\hline 7.0000 & 0.5000 & 0.5000 & 1.0000 & 1.0000 & 22.0000 & 23.0000 & 23.0000 \\
\hline 8.0000 & 0.5000 & 0.5000 & 1.0000 & 1.0000 & 22.0000 & 23.0000 & 23.0000 \\
\hline 9.0000 & 0.5000 & 0.5000 & 2.0000 & 2.0000 & 12.0000 & 14.0000 & 14.0000 \\
\hline 10.0000 & 0.5000 & 0.5000 & 2.0000 & 2.0000 & 12.0000 & 14.0000 & 14.0000 \\
\hline 11.0000 & 0.5000 & 0.5000 & 2.0000 & 2.0000 & 17.0000 & 19.0000 & 19.0000 \\
\hline 12.0000 & 0.5000 & 0.5000 & 2.0000 & 2.0000 & 17.0000 & 19.0000 & 19.0000 \\
\hline 13.0000 & 0.5000 & 0.5000 & 2.0000 & 2.0000 & 21.0000 & 23.0000 & 23.0000 \\
\hline 14.0000 & 0.5000 & 0.5000 & 2.0000 & 2.0000 & 21.0000 & 23.0000 & 23.0000 \\
\hline 15.0000 & 0.5000 & 0.5000 & 2.0000 & 2.0000 & 21.0000 & 23.0000 & 23.0000 \\
\hline 16.0000 & 0.5000 & 0.5000 & 2.0000 & 2.0000 & 21.0000 & 23.0000 & 23.0000 \\
\hline 17.0000 & 0.7500 & 0.2500 & 2.0000 & 4.0000 & 10.0000 & 14.0000 & 12.0000 \\
\hline 18.0000 & 0.7500 & 0.2500 & 2.0000 & 4.0000 & 10.0000 & 14.0000 & 12.0000 \\
\hline 19.0000 & 0.7500 & 0.2500 & 2.0000 & 4.0000 & 15.0000 & 19.0000 & 17.0000 \\
\hline 20.0000 & 0.7500 & 0.2500 & 2.0000 & 4.0000 & 15.0000 & 19.0000 & 17.0000 \\
\hline 21.0000 & 0.7500 & 0.2500 & 2.0000 & 4.0000 & 19.0000 & 23.0000 & 21.0000 \\
\hline 22.0000 & 0.7500 & 0.2500 & 2.0000 & 4.0000 & 19.0000 & 23.0000 & 21.0000 \\
\hline 23.0000 & 0.7500 & 0.2500 & 2.0000 & 4.0000 & 19.0000 & 23.0000 & 21.0000 \\
\hline 24.0000 & 0.7500 & 0.2500 & 2.0000 & 4.0000 & 19.0000 & 23.0000 & 21.0000 \\
\hline $\begin{array}{l}25.0000 \\
26.0000\end{array}$ & $\begin{array}{l}0.4375 \\
0.4375\end{array}$ & $\begin{array}{l}0.5625 \\
0.5625\end{array}$ & $\begin{array}{l}5.0000 \\
5.0000\end{array}$ & $\begin{array}{l}5.0000 \\
5.0000\end{array}$ & $\begin{array}{l}14.0000 \\
16.0000\end{array}$ & $\begin{array}{l}19.0000 \\
21.0000\end{array}$ & $\begin{array}{l}19.0000 \\
21.0000\end{array}$ \\
\hline 27.0000 & 0.4375 & 0.5625 & 5.0000 & 5.0000 & 16.0000 & 21.0000 & 21.0000 \\
\hline 28.0000 & 0.4375 & 0.5625 & 5.0000 & 5.0000 & 16.0000 & 21.0000 & 21.0000 \\
\hline 29.0000 & 0 & 0 & 0 & 0 & 0 & 0 & 0 \\
\hline 30.0000 & 0 & 0 & 0 & 0 & 0 & 0 & 0 \\
\hline 31.0000 & 0 & 0 & 0 & 0 & 0 & 0 & 0 \\
\hline 32.0000 & 0 & 0 & 0 & 0 & 0 & 0 & 0 \\
\hline 33.0000 & 0.8594 & 0.1406 & 3.0000 & 10.0000 & 9.0000 & 19.0000 & 12.0000 \\
\hline 34.0000 & 0.8594 & 0.1406 & 3.0000 & 10.0000 & 9.0000 & 19.0000 & 12.0000 \\
\hline 35.0000 & 0.9209 & 0.0791 & 3.0000 & 15.0000 & 9.0000 & 24.0000 & 12.0000 \\
\hline 36.0000 & 0.9209 & 0.0791 & 3.0000 & 15.0000 & 9.0000 & 24.0000 & 12.0000 \\
\hline 37.0000 & 0.9555 & 0.0445 & 3.0000 & 20.0000 & 9.0000 & 29.0000 & 12.0000 \\
\hline 38.0000 & 0.9555 & 0.0445 & 3.0000 & 20.0000 & 9.0000 & 29.0000 & 12.0000 \\
\hline 39.0000 & 0.8999 & 0.1001 & 6.0000 & 21.0000 & 0 & 21.0000 & 6.0000 \\
\hline 40.0000 & 0 & 0 & 0 & 0 & 0 & 0 & 0 \\
\hline 41.0000 & 0.5671 & 0.4329 & 12.0000 & 5.0000 & 0 & 5.0000 & 12.0000 \\
\hline 42.0000 & 0.5671 & 0.4329 & 12.0000 & 5.0000 & 0 & 5.0000 & 12.0000 \\
\hline 43.0000 & 0 & 0 & 0 & 0 & 0 & 0 & 0 \\
\hline 44.0000 & 0 & 0 & 0 & 0 & 0 & 0 & 0 \\
\hline 45.0000 & 0 & 0 & 0 & 0 & 0 & 0 & 0 \\
\hline 46.0000 & 0 & 0 & 0 & 0 & 0 & 0 & 0 \\
\hline 47.0000 & 0 & 0 & 0 & 0 & 0 & 0 & 0 \\
\hline 48.0000 & 0 & 0 & 0 & 0 & 0 & 0 & 0 \\
\hline$\gg 1$ & & & & & & & \\
\hline
\end{tabular}

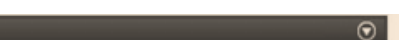

Figure 10. Output for testability model of a 4-bit comparator - MATLAB window \& digital system. 


\section{Acknowledgement}

The authors would like to express their great appreciations and gratitude to Sultan Qaboos University, Sultanate of Oman for providing research facilities, technical supports and research environment.

\section{References}

1. The International Technology Roadmap for Semiconductors 2013, (link last opened on August 28, 2014) http://www.itrs. net/Links/2013ITRS/Home2013.htm

2. Ahmad A. Testing of Complex Integrated Circuits (ICs)The Bottlenecks and Solutions. Asian J Inform Tech. 2005; 4(9):816-22.

3. Ahmad A, Al-Mashari A, Al-Lawati AMJ. On locking conditions in $\mathrm{m}$-sequence generators for the use in digital watermarking. Proceedings on International Conference on Methods and Models in Computer Science (ICM2CS09); 2009 Dec 14-15; Delhi. IEEE; 2009. p. 111-5.

4. Jamil T, Ahmad, A. An investigation in to the application of linear feedback shift registers for steganography. Proceedings IEEE on SoutheastCon, 2002; 2002 Apr 5-7; Columbia, SC, USA. IEEE; 2002. p. 239-44.

5. Ahmad A, Al-Busaidi S, Al-Mushrafi MJ. A new algorithmic procedure to test $\mathrm{m}$-sequence generating feedback connections of stream cipher's LFSRs. Proceedings of IEEE Region 10 International Conference, TENCON 2001, on Electrical and Electronic Technology. 2001 Aug 19-21; 1:366-9.

6. Ahmad A, Al-Busaidi S, Al-Mushrafi MJ. Design and study of a strong crypto-system model for e-commerce. Proceedings of the $15^{\text {th }}$ International Conference on Computer Communication. 2002; 619-30.

7. Bierman H. VLSI Test Gear Keeps with Chip Advances Special Report. Electronics. 1984; 125-8.

8. Ahmad A, Al-Busaidi SS, Al-Musharafi MJ. On Properties of PN Sequences Generated By LFSR - A Generalized Study and Simulation Modeling. Indian Journal of Science and Technology. 2013; 6(10):5351-8.

9. Ahmad A, Hayat L. Selection of Polynomials for Cyclic Redundancy Check for the Use of High Speed Embedded An Algorithmic Procedure. WSEAS Transactions on Computers. 2011; 10(1):16-20.

10. Hsin-Wen T, Soon-Jyh C, Su-Ling H. A design of linearity built-in self-test for current-steering DAC. J Electron Test. 2011; 27(1):85-94.

11. Ahmad A. A simulation experiment on a built-in self test equipped with pseudorandom test pattern generator and Multi-Input Shift Register (MISR). International Journal of VLSI Design and Communication Systems. 2011; $1(4): 1-12$.
12. Ahmad A. A Simulation Experiment On a Built-In Self Test Equipped with Pseudorandom Test Pattern Generator and Multi-Input Shift Register (MISR), ACEEE International Journal of VLSI Design \& Communication Systems (VLSICS). 2010; 1(4):1-12.

13. Ahmad A, Al-Abri D. Design of an Realistic Test Simulator for Built-In Self-Test Environment. J Eng Res. 2010; 7(2):69-79.

14. Ahmad A, Al-Abri D. Design of an Optimal Test Simulator for Built-In Self-Test Environment. J Eng Res. 2010; 7(2):69-79.

15. Ahmad A,Al-MaashriA.Investigating SomeSpecial Sequence Length Generated Through an External Exclusive-NOR Type LFSRs. Int J Electr Comput Eng. 2008; 34(4):270-80.

16. Ahmad A. Investigation of Typical Properties of Some LFSR Structures. Journal of System Science and Engineering. 2008; 17(1):65-9.

17. Ahmad A. Achievement of Higher Testability Goals through the Modification of Shift Registers In LFSR-based Testing. Int J Electron. 1997; 82(3):249-60.

18. Ahmad A. Critical role of polynomial seeds on the effectiveness of an LFSR-based testing technique. Int J Electron. 1994; 77(2):127-37.

19. Ahmad A, Nanda NK, Garg K. The use of irreducible characteristic polynomials in an LFSR based testing of digital circuits. Proceedings of $4^{\text {th }}$ IEEE International Conference of Region 10 (TENCON-89); 1989 Nov 22-24; Bombay. IEEE; 1989. p. 494-6.

20. Bardell PH e1 al. Built -In Test for VLSI: Pseudo-Random Techniques. Wiley; 1987.

21. Miczo A. Digital Logic Testing \& Simulation. 2nd ed. Hoboken, New Jersey: John Wiley and sons; 2003.

22. Mc-Cluskey EJ. Built-in self-test techniques. IEEE Design \& Test of Computers. 1985; 2(2):21-8.

23. Bennets RG. Design of Testable Logic Circuits. AddisonWesley Pub Company; 1984.

24. Williams TW. VLSI Testing. IEEE Computer. 1984; 17(10):126-36.

25. Abadir MS, Reghbati HK. LSI Testing Techniques. IEEE Micro. 1983; 3(1):34-51.

26. Williams TW, Parker KP. Design for Testability - A Survey. IEEE Proceedings. 1983; 71(1):98-112.

27. Bennets RG. Introduction to Digital Board Testing. New York: Crane Russak Ltd; 1981.

28. Muehldrof EI, Savakar AD. LSI Logic Testing - An Overview. IEEE Trans Comput. 1981; C-30(1):1-17.

29. Han J, Hao C, Erin B, José F. Reliability evaluation of logic circuits using probabilistic gate models. Microelectron Reliab. 2011; 51(2):468-76.

30. Ahmad A, Al-Lawati AMJ, Al-Naamany AM. Identification of test point insertion location via comprehensive knowledge 
of digital system's nodal controllability through a simulated tool. Asian J Inform Tech. 2004; 3(3):142-7.

31. Ahmad A, Al-Lawati A. Realization of a simplified controllability computation procedure-a MATLAB-SIMULINK based tool. Journal for Scientific Research-Science and Technology. 2003; 8:131-43.

32. Goldstein LH. Controllability/Observability Analysis of Digital Circuits. IEEE Trans CAS. 1979 Sep; CAS26(9):685-93.

33. Parker PK, McCluskey EJ. Probabilistic treatment of general combinational networks. IEEE Trans Comput. 1975; 100(6):668-70.
34. Ahmad A, Al-Musharafi MJ, Al-Busaidi S. Study and implementation of properties of $\mathrm{m}$-sequences in MATLABSIMULINK - A pass / fail test tool for designs of random generators. Journal of Scientific Research - Science and Technology. 2002; 7(1):147-56

35. Ahmad A, Al-Musharafi MJ, Al-Busaidi SS. Study and Implementation of Properties of $\mathrm{m}$-sequences in MATLABSIMULINK - A Pass / Fail Test Tool for Designs of Random Generators. Indian Journal of Science and Technology. 2013 Oct; 6(10):5351-8. 